\title{
Assessing BCG vaccination coverage and incidence of paediatric tuberculosis following two major changes in BCG vaccination policy in France
}

J P Guthmann (jp.guthmann@invs.sante.fr) ${ }^{1}$, D Antoine ${ }^{1}$, L Fonteneau ${ }^{1}$, D Che ${ }^{1}$, D Lévy-Bruhl ${ }^{1}$

1. French Institute for Public Health Surveillance (Institut de Veille Sanitaire, InVS), Saint-Maurice, France

Citation style for this article:

Guthmann JP, Antoine D, Fonteneau L, Che D, Lévy-Bruhl D. Assessing BCG vaccination coverage and incidence of paediatric tuberculosis following two major changes in BCG vaccination policy in France. Euro Surveill. 2011;16(12):pii=19824. Available online: http://www.eurosurveillance.org/ViewArticle. aspx?Articleld $=19824$

Article published on 24 March 2011

We report data on BCG vaccination coverage and paediatric tuberculosis (TB) incidence collected after the disappearance of the multipuncture device for BCG vaccination in January 2006 and the shift from universal to targeted vaccination in July 2007 in France. Vaccination coverage estimates in children for whom BCG is recommended allow assessing whether the recommendations are followed by doctors and/or accepted by the target population. In January and February 2006, BCG sales to the private sector in îlede-France region were $74.2 \%$ and $41.3 \%$ of the ones for the same months the previous year. Total sales in 2006 amounted to $57.3 \%$ of those in $\mathbf{2 0 0 5}$. Coverage decreased immediately after withdrawal of the multipuncture device, and remained generally insufficient in high risk children in the following years. However, the impact on paediatric TB incidence in 2008 seems very limited, although the duration of follow-up is still short. Training of doctors in intra-dermal vaccination and communication on the new vaccination policy should be strengthened.

\section{Background}

In France, until July 2007, primary BCG immunisation was mandatory for children before entering daycare centres or being taken care of by child minders and at the latest at the age of six, when school becomes compulsory. BCG was also recommended in the first month of life, for high risk children [1]. Until the end of 2005 , the vaccine was applied by using a multipuncture device (Monovax, Sanofi Pasteur MSD, France), whereby several needles simultaneously introduced the vaccine intradermally. In January 2006, this multipuncture device was removed from the French market and replaced by an intradermal Bacille Calmette-Guérin (BCG) device (Statens Serum Institut - SSI, Denmark), the technique recommended by the World Health Organization (WHO) [2]. The main reason for the withdrawal was that the production process of Monovax did no longer fulfill the standards required by the European regulation bodies [3]. Taking into account the important efforts needed to respond to these requirements and considering that France was one of the last countries in Europe to use the multipuncture technique [4], the manufacturer decided to cease the production. However, the difficulty of untrained medical staff to use the intradermal technique in young infants as well as its less favourable safety profile compared with the multipuncture technique, led to an estimated $54 \%$ decrease in BCG coverage, despite the still mandatory vaccination [5].

In July 2007, the mandatory BCG vaccination for all children was replaced by a strong recommendation to vaccinate only children considered at high risk of tuberculosis (TB) [6]. The decision to shift from universal to targeted vaccination was taken by the French government after a consultation of bodies involved in TB control and a multidisciplinary assessment of the impact of a vaccination policy change on the incidence of TB and the social acceptability of a BCG vaccination strategy targeting high risk children [7]. The main rationale for the change was the decreasing incidence of TB in France from more than 30,000 cases notified in 1972 to about 6,000 in 2005 and the heterogeneity of risk of disease [7]. On the one hand, the incidence of the disease had significantly decreased and was very close to the threshold values proposed by the International Union Against Tuberculosis and Lung Diseases for possible discontinuation of BCG vaccination $[7,8]$, on the other, the incidence of TB was much higher in some groups of the population. For example, the incidence of TB in people born abroad (foreignborn) was eightfold higher compared with those born in France (41.5 per 100,000 population versus 5.0 ) in 2005 [9]. Therefore, target groups for BCG vaccination are mainly children who were born, or whose parents were born, in TB-endemic countries or with a family history of TB. The high risk group also includes children, irrespective of the country of birth, living in the two French regions with the highest incidence of TB: French Guiana, a French overseas department (22.6 per 100,000 in 2008) and île-de-France, a French mainland region (17.9 per 100,000 in 2008) [10]. The 2007 $B C G$ vaccination policy recommends vaccination of the target groups as soon as possible after birth, with a 
catch-up vaccination for non-vaccinated at risk children aged 15 years or less [6].

Following these changes, an estimation of BCG vaccination coverage in the group of children targeted by the new recommendations was needed, in order to assess whether they had been put into practice. Until 2007, BCG vaccination coverage was routinely estimated by analysing the information in health certificates of all children and filled-in by doctors in early childhood [11]. However, this method was no longer appropriate after the new recommendations because coverage was to be evaluated only for a fraction of children. We therefore used alternative approaches to perform an evaluation which aimed to assess the impact of the changes that occurred in 2006-2007 on BCG coverage in target groups. In this paper, we report both these results and the trends of paediatric TB incidence after the 20062007 changes and discuss possible implications for TB control.

\section{Methods}

Estimation of tuberculosis vaccination coverage from BCG sales, 2005-2009

Vaccine sales to the private and public sector are used by the French Institute for Public Health Surveillance (Institut de Veille Sanitaire, InVS) as an indirect indicator of vaccination coverage in France. The Groupement pour l'Elaboration et la Réalisation de Statistiques (GERS, Partnership to Collect and Prepare Statistics) compiles data from the pharmaceutical industry every month and provides data of BCG sales to private pharmacies, which cover more than $90 \%$ of vaccine sales outside île-de-France and about $60-70 \%$ of sales in îlede-France. Sales to the public sector, mainly to maternal and child health clinics (MCHC), are provided by Sanofi Pasteur MSD which markets SSI BCG in France.
For île-de-France, where BCG vaccination is recommended for every child, vaccination sales grossly reflect vaccination coverage. We estimated vaccination coverage based on the number of vaccines sold and assuming that one vial of SSI BCG is used to vaccinate one child in the private sector and an average of 1.5 children in the public sector (D. Lévy-Bruhl, personal communication, Oct 2006). We report BCG sales after 2005 by month, compared with the respective month of 2005, which was taken as reference, since up to the end of 2005 , virtually all children were vaccinated before reaching six years of age. It was not possible to compare data for earlier years because they included revaccination which was discontinued in 2004 .

Outside Île-de-France, BCG sales cannot be used to estimate vaccination coverage trends because the number of children in the target population is unknown and the decrease in vaccine sales mainly reflects the decrease in the number of children for whom vaccination has been recommended since July 2007.

Survey in the private sector, February 2008

We performed a retrospective cross-sectional survey among general practitioners and paediatricians. This survey was performed seven months after the change in vaccination policy, with the objective of providing a timely follow-up of the new recommendations for the Ministry of Health. The targeted general practitioners and paediatricians belonged to a well organised network of physicians who are particularly aware of recent changes in the field of vaccination (convenience sample). Thus they form a special group which is not representative for physicians in general. They were asked to fill in a structured online questionnaire where demographic information, information on previous BCG vaccination and reasons for non-vaccination were

\section{FIGURE}

Percentage of Bacille Calmette-Guérin (BCG) sales to private pharmacies in Île-de-France between January 2006 and December 2009 compared with the same month of 2005

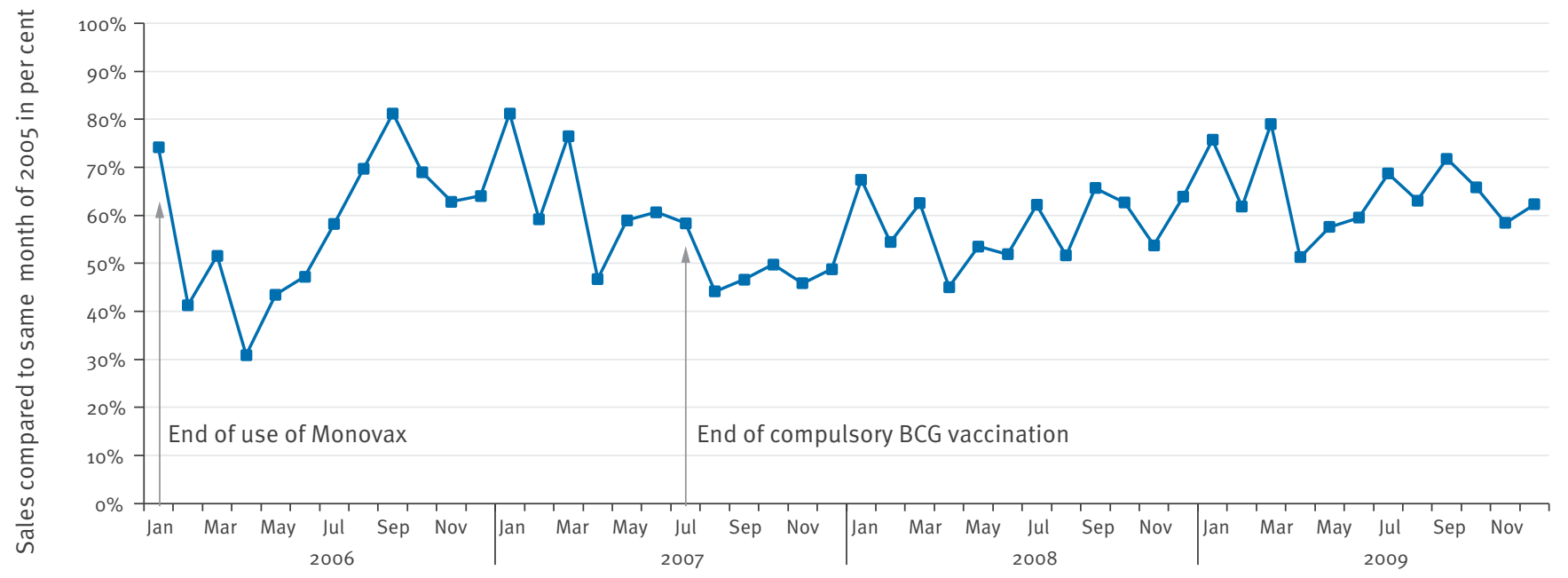

Note: BCG sales to private pharmacies cover more than $90 \%$ of vaccine sales outside île-de-France and about $60-70 \%$ of sales in Île-de-France. Source: Groupement pour l'Elaboration et la Réalisation de Statistiques (GERS) 
collected. Each doctor was asked to recruit, during his or her medical consultation, at least six consecutive at risk children aged two to seven months (born after BCG policy change) and eight to 23 months (born after withdrawal of Monovax and before BCG policy change). This stratification was made in order to estimate vaccination coverage separately in the two age groups. We allowed a two months delay to give a child the chance to be vaccinated and set a lower age limit of two months because this is the usual starting age for vaccinations in France. The full methodology, results and limitations of this survey are reported elsewhere [12].

Survey in the public sector, May 2009

We performed a retrospective cross-sectional survey in a random sample of at-risk children born after the change of vaccination policy i.e. after July 2007, and recruited at $\mathrm{MCHC}$ by physicians during medical consultation. This survey was conducted under the assumption that children taken care of by the public sector were likely to have a different coverage i.e. higher coverage than children vaccinated in the private sector. It would therefore complete the picture of vaccination coverage in the at-risk population in France. The full methodology and results of this survey are reported elsewhere [13]. Children were selected through a twostage random sampling in île-de-France (first stage: MCHC; second stage: patients) and a three-stage random sampling outside île-de-France, where we first selected a district and then MCHC within districts. We stratified children in two age groups to see whether younger children, aged two to 12 months at the time

TABLE 1

Number of children vaccinated with Bacille Calmette-Guérin (BCG) in the private and public sector, Île-de-France, 2005-2009

\begin{tabular}{|c|c|c|c|c|c|c|}
\hline & \multicolumn{5}{|c|}{ Number of children vaccinated } & \multirow{2}{*}{ Variation 2009-2005 } \\
\hline & 2005 & 2006 & 2007 & 2008 & 2009 & \\
\hline \multicolumn{7}{|c|}{ Private sector } \\
\hline Monovax & 158,108 & 0 & 0 & 0 & 0 & \\
\hline BCG SSI & 11,796 & 97,623 & 94,611 & 97,772 & 108,905 & \\
\hline Total & 169,904 & 97,623 & 94,611 & 97,772 & 108,905 & $-36 \%$ \\
\hline \multicolumn{7}{|c|}{ Public sector } \\
\hline Monovax & 47,733 & 0 & 0 & 0 & 0 & \\
\hline BCG SSI ${ }^{a}$ & 16,959 & 63,705 & 53,548 & 53,739 & 57,989 & \\
\hline Total & 64,692 & 63,705 & 53,548 & 53,739 & 57,989 & $-10 \%$ \\
\hline Total & 234,596 & 161,328 & 148,159 & 151,511 & 166,894 & $-29 \%$ \\
\hline
\end{tabular}

BCG: Bacille Calmette-Guérin; SSI: Statens Serum Institut.

a Number of children based on assumption of 1.5 children vaccinated per vial of BCG SSI in the public sector.

Source: Groupement pour l'Elaboration et la Réalisation de Statistiques (GERS), Sanofi Pasteur MSD.

\section{TABLE 2}

Bacille Calmette-Guérin (BCG) vaccination coverage in Île-de-France ( $\mathrm{n}=286)$ and outside Île-de-France ( $\mathrm{n}=122)$ in children at risk for whom BCG is recommended, data from general practitioners and paediatricians, France, February 2008

\begin{tabular}{|c|c|c|c|c|c|c|}
\hline \multirow{2}{*}{ Age (months) } & \multicolumn{2}{|c|}{$\begin{array}{l}\text { Children at risk living } \\
\text { in T̂le-de-France }(n=286)\end{array}$} & \multicolumn{2}{|c|}{$\begin{array}{c}\text { Children at risk living } \\
\text { outside île-de-France }(n=122)\end{array}$} & \multicolumn{2}{|c|}{$\begin{array}{l}\text { Children at risk living } \\
\text { in France }(n=408)\end{array}$} \\
\hline & $\mathrm{N}$ & Coverage* & $\mathrm{N}$ & Coverage* $^{*}$ & $\mathrm{~N}$ & Coverage* \\
\hline $2-7$ & 144 & $51.4 \%$ & 64 & $39.9 \%$ & 208 & $44.8 \%$ \\
\hline $8-23$ & 142 & $79.8 \%$ & 58 & $82.8 \%$ & 200 & $81.1 \%$ \\
\hline Total & 286 & $67,4 \%$ & 122 & $56.8 \%$ & 408 & $62.1 \%$ \\
\hline
\end{tabular}

* Proportion adjusted for age, speciality and region of residency of the doctor.

Source: InVS (Institut de Veille Sanitaire, Saint Maurice, France) ACTIV.

\section{TABLE 3}

Bacille Calmette-Guérin (BCG) vaccination coverage in Île-de-France ( $\mathrm{n}=481)$ and outside Île-de-France $(\mathrm{n}=375)$ in children at risk for whom BCG is recommended, data from maternal and child health clinics, France, May 2009

\begin{tabular}{|c|c|c|c|c|c|c|}
\hline \multirow{2}{*}{ Age group } & \multicolumn{2}{|c|}{$\begin{array}{l}\text { Children at risk living } \\
\text { in T̂le-de-France }(n=481)\end{array}$} & \multicolumn{2}{|c|}{$\begin{array}{l}\text { Children at risk living } \\
\text { outside Île-de-France }(n=375)\end{array}$} & \multicolumn{2}{|c|}{$\begin{array}{l}\text { Children at risk living } \\
\text { in France }(n=856)\end{array}$} \\
\hline & Coverage & $95 \% \mathrm{Cl}$ & Coverage & $95 \% \mathrm{Cl}$ & Coverage & $95 \% \mathrm{Cl}$ \\
\hline 2-12 months & $86.7 \%$ & $75.0-93.4$ & $53.1 \%$ & $44.6-61.5$ & $66.2 \%$ & $59.1-72.7$ \\
\hline $13-23$ months & $95.0 \%$ & $86.3-98.3$ & $75.5 \%$ & $62.5-85.1$ & $83.0 \%$ & $74.2-89.2$ \\
\hline Total & $89.8 \%$ & $81.4-94.7$ & $61.7 \%$ & $53.8-69.0$ & $72.6 \%$ & $66.3-78.0$ \\
\hline
\end{tabular}

$\mathrm{Cl}$ : Confidence interval.

Source: InVS (Institut de Veille Sanitaire, Saint Maurice, France). 
of the survey, were better vaccinated than older children, aged from 13 to 23 months, and hence to evaluate whether compliance with new recommendations was improving over time. The information collected was similar to that of the survey in the private sector.

For both the private and the public surveys, as well as for TB incidence, we present figures separately for îlede-France, as this is the only region of mainland France where BCG remains recommended for all children.

\section{Childhood tuberculosis incidence in 2008}

TB is mandatorily notifable in France and case-based data are collected and analysed at the Institut de veille sanitaire (InVS). Patients are notified if they have clinical and/or radiological signs of TB and are treated, irrespective if TB was confirmed by culture or not. We restricted our analysis to TB cases aged less than three years-old in 2008, since they were born after the withdrawal of Monovax and thus the impact of the changes is likely to be observed in this group. We estimated both the proportion of cases and severe cases, i.e.meningitis and miliary TB, that belong to the at-risk population and their vaccination status. Information about miliary TB and at-risk status for children aged less than 15 years are collected only since 2007 when the mandatory notification form was modified.

\section{Results}

\section{Estimation of children vaccinated}

from BCG sales

Withdrawal of Monovax in January 2006 led to an immediate and sharp decrease in BCG sales. In January and February 2006, BCG sales to the private sector in île-de-France were 8,435 and 5,196 vaccines respectively (2005: 11,374 and 12,583 vaccines), $74.2 \%$ and $41.3 \%$ of those for the same months the previous year (Figure). Overall, total sales in 2006 amounted to $57.3 \%$ of those in 2005 . This sharp decrease preceded the policy change in July 2007. In 2009, the estimated number of children vaccinated with BCG was $29 \%$ lower than in 2005 , but showed a slight increase when compared with 2006, 2007 and 2008 when the decrease was $31 \%, 37 \%$ and $35 \%$, respectively (Table 1 ). The decrease from 2005-2009 was significantly higher in the private $(-36 \%)$ than in the public $(-10 \%)$ sector (p<0.001).
Survey in the private sector, February 2008

Among children in whom BCG was recommended and who were born after the change in vaccination policy (two to seven months-old), $51.4 \%$ had been vaccinated in île-de-France and $39.9 \%$ outside Île-de-France seven months after this change. Vaccination coverage was higher in children eight to 23 months-old and born between the withdrawal of Monovax and the change in vaccination policy (79.8 and $82.8 \%$ respectively in and outside île-de-France) (Table 2).

\section{Survey in the public sector, May 2009}

Vaccination coverage in children at risk was overall $72.6 \%$ (95\% confidence interval (Cl): $66.3-78.0$ ). It was $89.8 \%$ (95\% Cl: $81.4-94.7)$ in Île-de-France and $61.7 \%$ (95\% Cl: 53.8 - 69.0) outside île-de-France (Table 3). Children, aged 13-23 months, had higher vaccination coverage compared with children aged two to 12 months, however this difference was only statistically significant outside Île-de-France ( $p<0.01)$.

\section{Tuberculosis incidence in 2008}

In 2008, 105 newly diagnosed cases of TB were reported in France in children aged less than three years (Table 4). In Île-de-France, 43 new cases were reported, a figure comparable with the average annual number of cases for the years 2000-2005 (45 cases) (InVS, unpublished data). No case was reported in children aged less than three years in French Guiana in 2008. The 62 cases reported outside île-de-France in 2008 , represent an increase compared with the average annual number of cases for the years 2000-2005 (46 cases). Of the 105 newly diagnosed cases in children aged less than three years reported in 2008, $75 \%$ (79 cases) belonged to the at-risk group: $100 \%$ ( 43 cases) in île-de-France and $58 \%$ (36 of 62 cases) outside Îlede-France. Twenty of 43 and five of 36 cases were vaccinated respectively. In Île-de-France, five of 43 cases were not vaccinated and for 18 vaccination status was unknown; outside île-de-France 23 of 36 cases were not vaccinated and information was not available for eight. In 2008, three miliary TB and no TB meningitis cases were detected in under three year-olds. Of these three cases, two were at risk (family history of TB for one child and father born in a TB endemic country for both) and were unvaccinated. The vaccination status of the third child was unknown. These figures are very close to those reported in the three previous years. In

\section{TABLE 4}

Number of tuberculosis cases reported in children aged less than three years old by region, France (French Guiana not included), 2000-2008

\begin{tabular}{|l|c|c|c|c|c|c|c|c|c|c|}
\hline Region & \multicolumn{9}{|c|}{ Year } \\
\hline île -de-France & 2000 & 2001 & 2002 & 2003 & 2004 & 2005 & 2006 & 2007 & 2008 & Average 2000-2005 \\
\hline Outside Île-de-France & 60 & 41 & 42 & 44 & 43 & 39 & 31 & 35 & 43 & 45 \\
\hline Total & 36 & 26 & 51 & 59 & 44 & 60 & 49 & 62 & 62 & 46 \\
\hline
\end{tabular}

Source: InVS (Institut de Veille Sanitaire, Saint Maurice, France). 
2005, three TB meningitis cases, one vaccinated, one non-vaccinated, one with unknown vaccination status were notified; in 2006 there were four TB meningitis cases, two vaccinated, two unvaccinated and in 2007 there were two vaccinated milliary TB cases and one non-vaccinated meningitis/milliary TB case.

\section{Discussion}

Estimates of BCG vaccination coverage in France, after the withdrawal of the multipuncture device for BCG (Monovax) in 2006 and the shift from universal vaccination to immunisation of children at risk in 2007, are essential to evaluate the new BCG vaccination policy. Vaccination coverage estimates in children in whom BCG is recommended allow assessing whether recommendations are followed by doctors and/or accepted by the target population. The number of newly diagnosed TB cases in small children informs on the possible impact of BCG coverage on the disease incidence. Our coverage figures, provided by three different sources of information, each with their own strengths and limitations [12-14], indicate insufficient vaccination coverage in children at risk of TB. This is especially true outside île-de-France where incidence is very low and for children followed in the private sector where the majority of childhood vaccinations are performed. Our figures show the greatest decrease in vaccination coverage after the shift from the multipuncture device to intradermal BCG application. The emphasis given in 2007 to vaccination of high risk children did not allow catch up for this decrease. The insufficient coverage indicates that further efforts are needed to improve implementation of vaccination against TB. Information from our previous surveys $[12,13]$ shows that target groups are not well identified and indications of vaccination are not always understood by doctors, and also that doctors may have difficulties in using the intradermal technique. This was especially the case in low incidence areas i.e. outside île-de-France, where practitioners are rarely confronted with at-risk children and therefore may lack practice of intradermal vaccination. To tackle this, their respective knowledge and practice should be strengthened through information about the new French BCG vaccination policy and on-going training in intradermal BCG vaccination.

An important question is whether the insufficient vaccination coverage will affect the incidence of TB and whether France is likely to experience a similar situation to countries such as Sweden, where universal BCG vaccination was discontinued in 1975 and replaced by a targeted vaccination $[15,16]$. After this change, BCG vaccination coverage in target groups remained low in Sweden (under $5 \%$ ), leading to a fifteenfold increase in TB incidence in children born to parents of foreign origin: from 2.6 per 100,000 in 1975 to 39.5 in 1980 . An increase in vaccination coverage in 1985 close to $80 \%$, led to a decrease in incidence in this group, although it was still higher than when BCG was given to all children.
Our data suggest a limited impact of the changes in BCG vaccination on the incidence of paediatric TB in France. Compared with 2005, when BCG coverage was close to $100 \%$, the number of cases in under three year-olds is almost unchanged (105 cases in 2008 vs. 101 cases in 2005). The slight increase of $2.3 \%$ in TB cases in 2008 when compared with 2007 , could be due to a real increase in the number of newly diagnosed TB cases, but could also reflect an improvement of the TB control programme which was reinforced in 2007 , with a better identification and reporting of cases. Moreover, the slight increase in cases observed in 2008 affected only the île-de-France region where the BCG coverage is better than elsewhere in France. This does not support a direct relationship between vaccination coverage and incidence of TB. Also, the number of meningitis/miliary TB cases remained very low in this age group.

The decision to change the vaccination strategy and the choice for universal or targeted vaccination or total interruption needs to be made after a risk-benefit analysis where the expected increase in the number of TB cases is weighted against the number of adverse vaccine events prevented by the reduction in vaccinations [17]. In France, the shift to a targeted strategy was made after an evaluation showing that if immunisation was restricted to children at risk with stable vaccination coverage in this population, this would result, 15 years after the change, in about 80 additional TB cases per year in the no longer vaccinated low risk population. This increase had to be balanced against the prevention of an estimated 10 disseminated BCG infections and 260 cases of BCG associated lymphadenitis $[7,18]$. These numbers would increase to around 200 additional TB cases, also affecting children at risk, and prevention of 12 disseminated BCG infections and 280 cases of lymphadenitis if coverage decreased to $50 \%$. The slight increase in the number of cases outside îlede-France in our data, of which the majority are not vaccinated, could reflect the anticipated impact of the discontinuation of BCG vaccination in low risk children. It is however too early to assess the full consequences of the low BCG coverage.

\section{Conclusion}

Measuring vaccination coverage is a key issue in public health surveillance, and following this indicator after a change in vaccination policy informs on whether the new policy is satisfactorily implemented. As other countries in Europe [19], France has reviewed its national BCG policy in 2007 and after having changed to intradermal BCG vaccination in 2006 already. Our assessment shows that BCG coverage is insufficient after these changes, although it is too early to assess the full consequences of this situation. The rather stable incidence of TB cases in children under three years of age in île-de-France and the very low number of severe cases reported in 2008 is reassuring, but the duration of follow-up is very limited. We need to remain vigilant and keep in mind that TB in high risk groups is still a challenge in France, given the European context where TB remains an important public health issue [20]. 


\section{References}

1. Conseil supérieur d'hygiène publique de France. [Vaccination schedule for 2005]. Bull Epidémiol Hebd. 2005; 29-30: 141-7. French.

2. World Health Organization (WHO). BCG vaccine. WHO position paper. Wkly Epidemiol Rec. 2004;79(4):27-38.

3. de La Rocque F, Cohen R, Vie Le Sage F, Bocquet A, Boucherat M, Levy Bruhl D. [French paediatrician and general practitioner's survey about actual and future BCG use]. Arch Pediatr. 2005;12(11):1665-9. French.

4. Manaouil C, Garnier C, Gignon M, Jardé O. [Tuberculosis vaccination programs: where are we?]. Arch Pediatr. 2008;15(6):1100-6. French.

5. Lévy-Bruhl D, Paty MC, Antoine D, Bessette D. Recent changes in tuberculosis control and BCG vaccination policy in France. Euro Surveill. 2007;12(37):pii=3268. Available from: http:// www.eurosurveillance.org/ViewArticle.aspx?Articleld $=3268$

6. Haut conseil de la santé publique. [Vaccination schedule for 2007 and recommendations published since the 2006 vaccination schedule]. Bull Epidémiol Hebd; 2007;31-32:271-7. French.

7. Lévy-Bruhl D. Prospects for the BCG vaccination programme in France. Euro Surveill. 2006;11(3):pii=605. Available from: http://www.eurosurveillance.org/ViewArticle. aspx?Articleld $=605$

8. Criteria for discontinuation of vaccination programmes using Bacille Calmette-Guerin (BCG) in countries with a low prevalence of tuberculosis. A statement of the International Union Against Tuberculosis and Lung Disease. Tuber Lung Dis. 1994;75(3):179-80.

9. Antoine D, Che D. Tuberculosis cases notified in France in 2005. Bull Epidémiol Hebd. 2007;11:85-9. French.

10. Antoine D, Che D. Epidemiology of tuberculosis in France: cases reported in 2008. Bull Epidemiol Hebd. 2010;27-28:28993. French.

11. Fonteneau L, Guthmann JP, Collet M, Vilain A, Herbet JB, LévyBruhl D. Vaccination coverage estimated based on data found in $24^{\text {th }}$ month health certificates of infants, France, 20042007. Bull Epidemiol Hebd. 2010;31-32:329-3. French.

12. Guthmann JP, de La Rocque F, Boucherat M, van Cauteren D, Fonteneau L, Lécuyer A, Cohen R, Lévy-Bruhl D. [BCG vaccine coverage in private medical practice: First data in children below two years old, seven months after the end of compulsory vaccination in France]. Arch Pediatr. 2009;16(5):489-95. French.

13. Guthmann JP, Fonteneau L, Desplanques L, Lévy-Bruhl D. [BCG vaccination coverage in children born after the end of compulsory BCG vaccination and followed in maternal and child health clinics in France: a national survey 2009]. Arch Pediatr. 2010;17(9):1281-7. French.

14. Guthmann JP, Fonteneau L, Antoine D, Cohen R, Lévy-Bruhl $D$, Che D. [BCG vaccination coverage and epidemiology of tuberculosis in children: where do we stand one year after suspending mandatory immunization, in France?]. Bull Epidemiol Hebd. 2009; 12-13:113-6. French.

15. Romanus V. First experience with BCG discontinuation in Europe. Experience in Sweden 15 years after stopping general BCG vaccination at birth. Bull Int Union Tuberc Lung Dis. 1990;65(2-3):32-5.

16. Romanus V, Svensson A, Hallander HO. The impact of changing BCG coverage on tuberculosis incidence in Swedishborn children between 1969 and 1989. Tuber Lung Dis. 1992;73(3):150-61.

17. Manissero D, Lopalco PL, Levy-Bruhl D, Ciofi Degli Atti ML, Giesecke J. Assessing the impact of different BCG vaccination strategies on severe childhood TB in low-intermediate prevalence settings. Vaccine. 2008;26(18):2253-59.

18. Lévy-Bruhl D. [Estimation of the epidemiological impact of various BCG vaccination scenarios in France]. Rev Epidemiol Sante Publique. 2005;53(5):501-8. French.

19. Jakab Z. Tuberculosis in the European Union - ongoing commitment needed to control the disease. Euro Surveill. 2009;14(11): pii=19150. Available from: http://www. eurosurveillance.org/ViewArticle.aspx?Articleld=19150

20. Watson JM. Tuberculosis and BCG in Europe. Euro Surveill. 2006;11(3):pii=603. Available from: http://www. eurosurveillance.org/ViewArticle.aspx?Articleld $=603$ 